\title{
TITLE:
}

\section{Lipase-catalyzed syntheses of sugar esters in non-aqueous media.}

$\operatorname{AUTHOR}(S)$ :

Kobayashi, Takashi

\section{CITATION:}

Kobayashi, Takashi. Lipase-catalyzed syntheses of sugar esters in nonaqueous media.. Biotechnology letters 2011, 33(10): 1911-1919

\section{ISSUE DATE:}

2011-10

URL:

http://hdl.handle.net/2433/147237

\section{RIGHT:}

The final publication is available at www.springerlink.com; This is not the published version. Please cite only the published version.; この論文 は出版社版でありません。引用の際には出版社版をご確認ご利用くだ さい。 


\title{
Lipase-catalyzed syntheses of sugar esters in non-aqueous media
}

Takashi Kobayashi $^{*}$

\begin{abstract}
The lipase-catalyzed reaction is useful to obtain sugar esters with chemically defined structures. The synthesis of sugar esters in non-aqueous media has been attempted for a quarter century. To facilitate the reactions, they have been performed either in an organic solvent with/without a polar adjuvant or in an ionic liquid, or by using a hydrophobic sugar derivative. In this review, the following points are discussed: 1) various synthetic methods of sugar esters; 2) role of the solvents or adjuvants; and 3) improvement in the productivity.
\end{abstract}

Keywords Lipase $\cdot$ Non-aqueous medium $\cdot$ Productivity $\cdot$ Sugar derivative $\cdot$ Sugar ester

*Corresponding author: T. Kobayashi

Division of Food Science and Biotechnology, Graduate School of Agriculture, Kyoto University, Sakyo-ku, Kyoto 606-8502, Japan

e-mail: tkoba@kais.kyoto-u.ac.jp 


\section{Introduction}

Daily necessities such as foods, cosmetics or medicines contain many esters. One of the more famous ones is triacylglycerol in olive oil, but there are many other esters including sugar esters which are dealt with in this review. In general, a sugar ester is used as an emulsifier. Because the types of constitutive fatty acid and sugar moieties of the sugar esters can be easily changed, their properties can widely vary; e.g., each sugar ester has a different critical micelle concentration (CMC) and hydrophilic-lipophilic balance (HLB) over a wide range.

There are various methods to efficiently synthesize esters, and the enzymatic syntheses of sugar esters are described in this review. The lipase-catalyzed synthesis of sugar esters by dehydrative condensation or transesterification can be relatively easily applied for food processing in comparison with the general organic ones from the viewpoint of safety because one of the organic ones is performed by adding acyl chloride into the mixture of a sugar, $N, N$-dimethylformamide (DMF), and pyridine. This synthesis also has an advantage that the product may be accepted by customers as a 'natural product'. Furthermore, the enzymatic method theoretically has characteristics that can introduce a fatty acid into a specific position of the sugar by taking advantage of the high substrate specificity.

Sugar esters used in industries are currently being manufactured by chemical syntheses. However, the current methods generally afford several isomers that have the different degrees of acylation and different acylated positions. Many trials have been done to synthesize the sugar esters with chemically defined structures. As one of these trials, the lipase-catalyzed synthesis is expected to be a promising method. In addition, the lipase-catalyzed synthesis can be performed under mild conditions and requires a fewer number of separating and refining steps.

\section{Sugar esters synthesized by lipase-catalyzed reaction}

In many cases, the aim of the addition of a fatty acid to sugars is the improvement of the compatibility between the sugar and fat. Based on these concepts, lipase-catalyzed syntheses have been performed to produce various sugar esters and related compounds (Table 1). The fatty acid ester of a monosaccharide or sugar alcohol attracted attention during the first decade of the lipase-catalyzed syntheses (Chopineau et al. 1988; Ikeda \& Kilbanov 1993; Khaled et al. 1991; Therisod \& Klibanov 1986). In these cases, glycerol or glucose, galactose, xylitol, sorbitol, etc., were mainly used as the sugar substrate. Whereas, an unsaturated fatty acid such as oleic acid or linoleic acid, a medium or long chain saturated fatty acid was often used as 


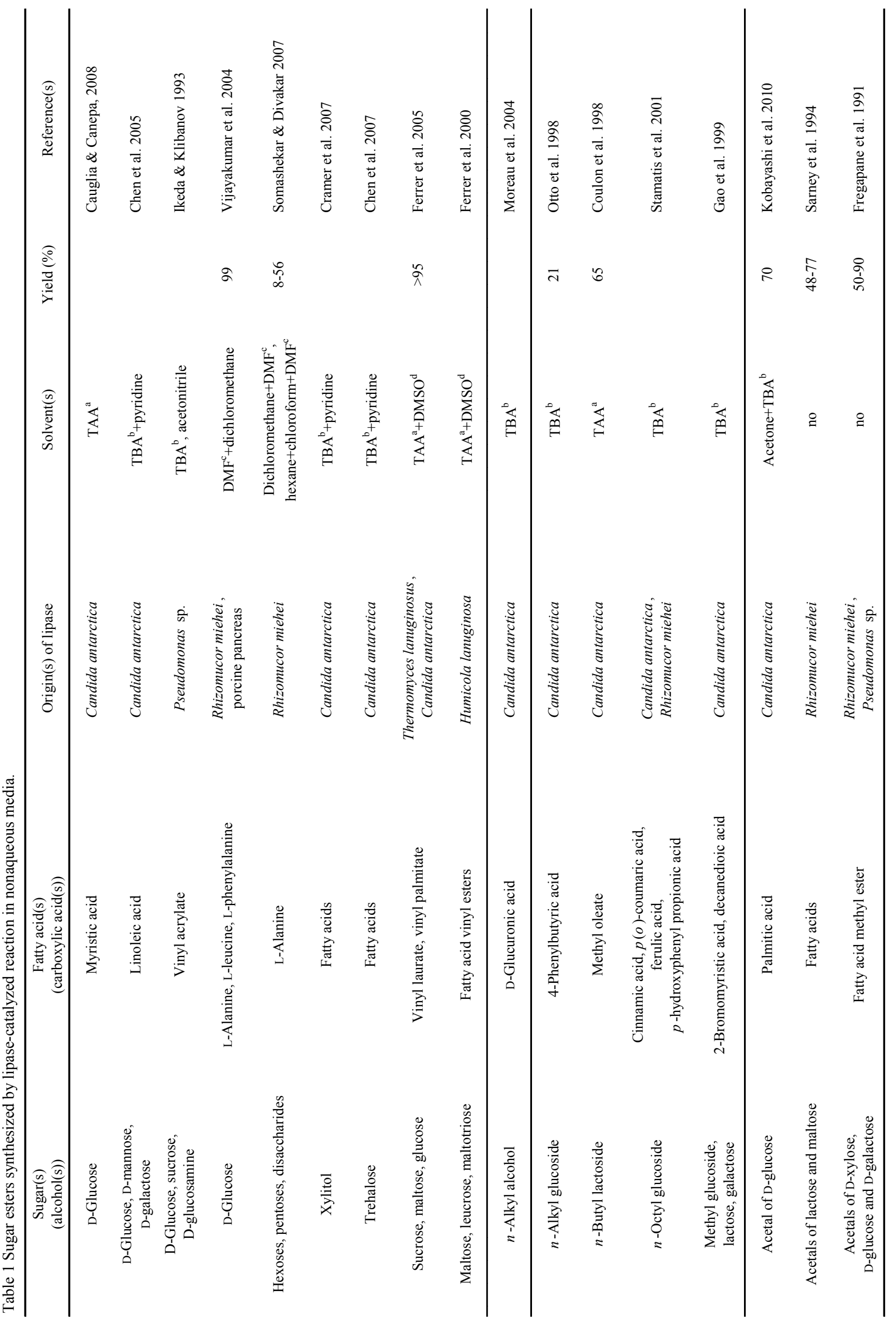




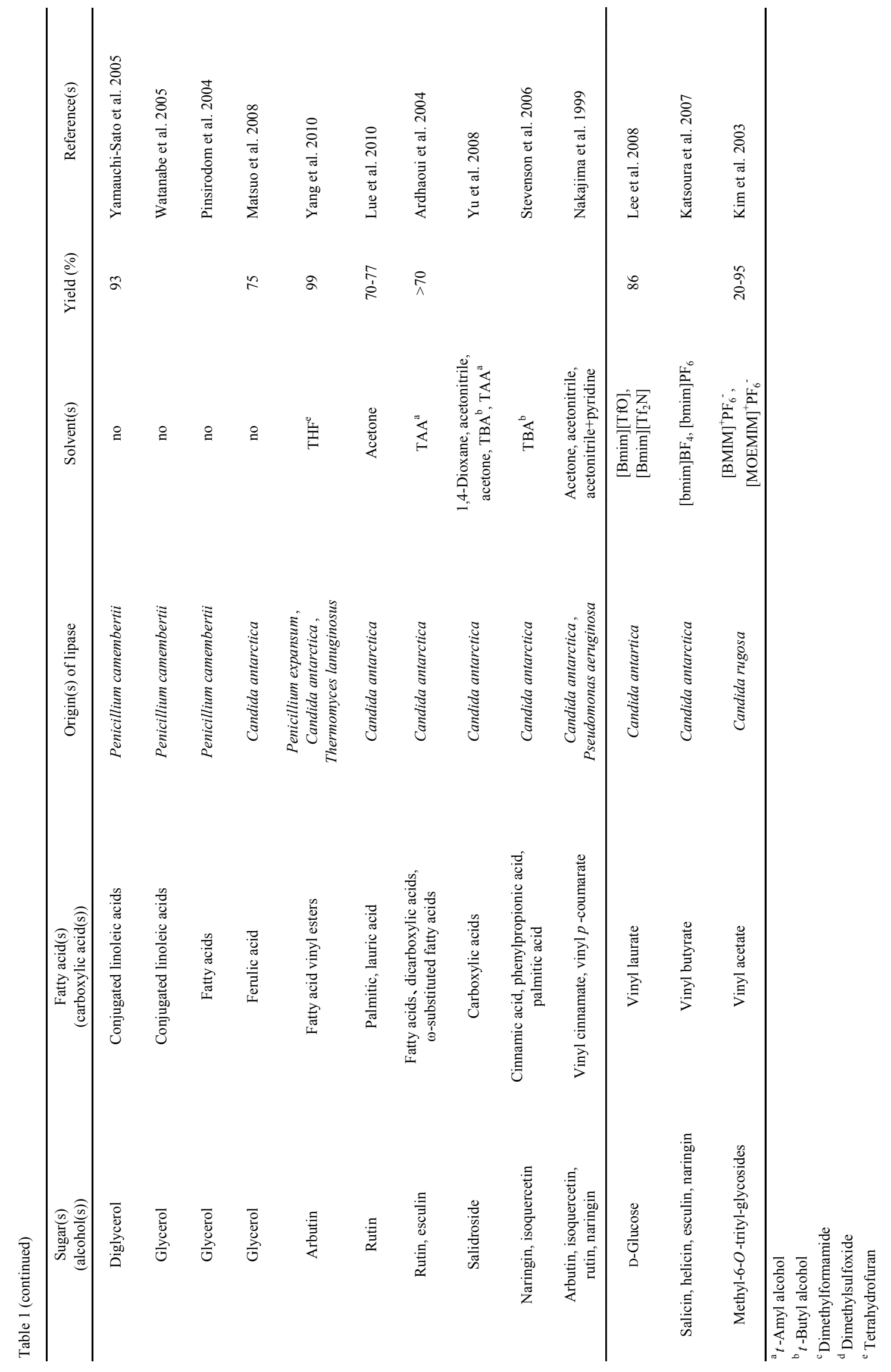


an acyl substrate.

In the first half of 1990 s, investigations emerged that synthesized sugar esters containing a disaccharide such as sucrose or lactose, maltose, an oligosaccharide such as maltotriose as a sugar moiety (Ferrer et al. 2000; Sarney et al. 1994; Sarney et al. 1996). The background for the trials using these syntheses suggested that sugar esters with a big carbohydrate moiety may have more desirable properties as an emulsifier. Relatively recently, polyphenolic glycoside esters have also been synthesized to improve the lipophilicity of the glycosides. In these cases, there is a trend to exploit the functionality of the glycosides by solubilizing the less soluble functional compounds in oil. In addition, there are many reports that adopted the lipase-catalyzed reactions as a part of the chemo-enzymatic synthesis, in which most of the reactions were often used for the purpose of taking advantage of the substrate specificity or that of planning an "improvement in productivity".

\section{Synthesis of esters in non-aqueous media}

When a sugar ester is synthesized by dehydrative condensation from a fatty acid and sugar, water is formed as a by-product (Scheme 1). To suppress the inverse reaction, i.e., hydrolysis, it is effective to perform the reaction in an environment containing little water, namely in a non-aqueous medium. In addition, for the transesterification, the reaction in a non-aqueous medium is also effective from the viewpoint of hydrolysis control; if water exists in a reaction system, hydrolysis also occurs in parallel with the transesterification.

Some researchers reported that certain enzymes show their catalytic activity in some organic solvents with a low water content (Klibanov, 1986; Klibanov, 1989; Therisod \& Klibanov 1986), and then the non-aqueous enzymatic reactions became noteworthy. Thereafter, the lipase-catalyzed synthesis has been tried in organic solvents for a quarter century. In addition, the synthesis of esters in an ionic liquid, the property of which is quite different from that of a general organic solvent, has also attracted attention in relatively recent years.

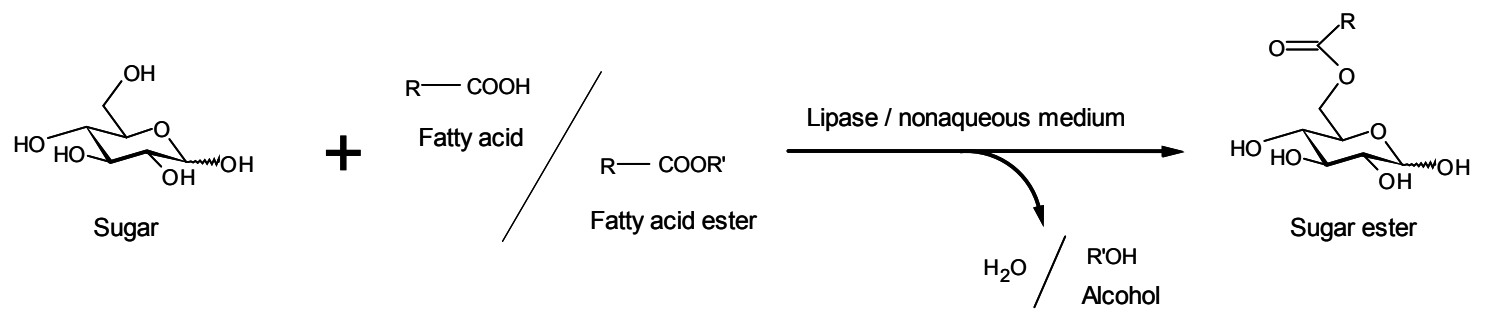

Scheme 1 Lipase-catalyzed synthesis of sugar ester in a non-aqueous medium 


\section{Synthesis in an organic solvent}

The synthesis in an organic solvent has the advantage that a high yield can be anticipated. However, there is a problem that the lipase easily inactivates. This problem limits the origin of the lipase and also makes its selection difficult at the same time. Lipases from Candida antarctica (fraction B; CALB), Rhizomucor miehei, Burkholderia cepacia, etc., are usually selected.

Next, more attention is paid to the type of organic solvents as the reaction medium. The available organic solvents are rather limited for the lipase-catalyzed reaction; hydrocarbons or nitriles, tertiary alcohols, ethers, ketones, aromatic solvents, etc., are usually used. Among them, relatively polar solvents have been used for the synthesis of the sugar esters; e.g., tertiary alcohols, nitriles, ketones. Use of these solvents is due to the low solubility of the sugars in the less polar solvents; e.g. the solubilities of glucose, fructose, and galactose in acetonitrile are 92.7, 978, $211 \mu \mathrm{mol} / \mathrm{L}$ (Watanabe et al. 2000). On the other hand, a polar solvent tends to easily inactivate a lipase. Based on these reasons, CALB is often practically used in many reactions because of the high activity in and the high tolerance toward polar solvents (Table 1).

However, even by using an approach of solvent selection, it is very difficult to synthesize the sugar esters of disaccharides and oligosaccharides at a practical level. The main reason is that the solubility of these sugars in these organic solvents becomes extremely low when the saccharide chain length increases. Therefore, an idea has been proposed using a highly polar solvent which easily dissolves both the fatty acid and saccharide, in which the use of dimethylsulfoxide (DMSO), DMF, pyridine, etc., has been tried. However, most lipases easily inactivate in these solvents in a pure form even if CALB is used. The reason may be due to the unfolding of the protein (Klyosov et al. 1975) or the removal of water to maintain the minimum catalytic activity of the lipase (Krishna et al. 2001).

To prevent inactivation of the lipase, it has been suggested that a small amount of these highly polar solvents is added to $t$-butyl alcohol (TBA) or to $t$-amyl alcohol (TAA) as an adjuvant (a co-solvent). Plou et al. (2002) reported that inactivation of the lipase is suppressed when the concentration of DMSO is below $20-30 \%$ in TAA. There are other reports adopting the mixed solvent system including a highly polar solvent such as TBA+pyridine or TAA+dimethylacetamide (Chen et al. 2005; Ferrer et al. 1999; Ferrer et al. 2005; Nakajima et al. 1999).

\section{Synthesis in an ionic liquid}

When a sugar ester is synthesized by a lipase in a general organic solvent, it is necessary to use an adjuvant 
to dissolve the sugars in some cases. In addition, organic solvents usually have a high volatility and are also harmful. To overcome these problems, the lipase-catalyzed reaction in an ionic liquid has attracted attention. An ionic liquid is formed as an asymmetric organic salt and is in liquid state below $100^{\circ} \mathrm{C}$ or close to room temperature. It also has the following characteristics: i) it is suitable for green chemistry because the vapor pressure is approximately zero, i.e., it is nonvolatile, ii) each ionic liquid has different properties because it is easy to change the combination of the cation and anion species of the ionic liquid, and iii) good choice of an ionic liquid contributes to both the high stability of the enzyme and the high dissolution of sugars (Diego et al. 2005; Kaar et al. 2003; Lozano et al. 2004; Zhao et al. 2008). Based on these characteristics, an ionic liquid has been studied as the reaction medium; e.g., Kim et al. (2003) performed the acetylation of the monoprotected glycosides, while Zhao et al. (2008) succeeded in the acylation of glucose and cellulose.

\section{Solvent-free reaction}

The reaction systems above introduced include a certain type of solvent or liquid as the adjuvant. However, it is possible to perform a reaction without any adjuvant under limited conditions (solvent-free system). For example, glycerol, a simple sugar alcohol, can be easily converted to acylglycerols by mixing with a fatty acid or an aromatic carboxylic acid in the presence of lipase (Matsuo et al. 2008; Pinsirodom et al. 2004; Watanabe et al. 2002; Watanabe et al. 2005). In addition, the ester of diglycerol can also be synthesized by mixing the substrates and lipase (Yamauchi-Sato et al. 2005). Although some esters can be synthesized in a solvent-free system, it is necessary to adopt another strategy to obtain other sugar esters when this reaction system is selected.

\section{Improvement in productivity}

It is necessary to achieve a higher productivity, namely, a high reaction rate and high product concentration, to facilitate the production of sugar esters. Various methods have been tried to achieve a high productivity. The first one is to improve the equilibrium yield. The second one is to raise the product concentration by increasing the substrate concentration, and the last one is to improve the reaction rate.

\section{Improvement of equilibrium yield}

There are several techniques to raise the equilibrium yield. The synthesis of esters by a lipase requires two substrates. The yield can be effectively raised by adding one of the substrates in excess. If one of the 
substrates is cheap and can be easily removed, this technique is the simplest and is often first evaluated in a general study. This technique is also effective for transesterifications.

The synthesis of esters by a lipase is a reversible reaction, and a by-product forms; i.e., water forms during dehydrative condensation, and an alcohol forms during transesterification. Therefore, the equilibrium yield can also be improved by removing these by-products from the reaction system. In these cases, methods are often adopted in which water or alcohol is removed in vacuo (Watanabe et al. 2002; Watanabe et al. 2005; Yamauchi-Sato et al. 2005) or by a desiccant such as molecular sieves (Ardhaoui et al. 2004; Cramer et al. 2007; Ferrer et al. 2005; Katsoura et al. 2007; Lue et al. 2010; Stamatis et al. 2001; Stevenson et al. 2006). Although the former one can be performed without any additive, its applications are limited only to a reaction involving a solvent-free system or in an ionic liquid.

The next example is a reaction using fatty acid vinyl esters (Table 1). The fatty acid moiety of the vinyl ester is incorporated into a target ester by transesterification, and vinyl alcohol forms as a by-product. Vinyl alcohol is a tautomer of acetaldehyde, but its existence mostly leans to the keto form (acetaldehyde) at normal temperature. Therefore, almost all of vinyl alcohol is virtually removed from the reaction system (Scheme 2). Because other enols having a longer alkyl chain also have their keto forms, a similar technique may theoretically improve the yield. However, there are few studies using the esters of these enols maybe due to the cost and acquisition of the ester as a raw material.

The properties of an organic solvent are next focused on. Equilibrium yields usually depend on the
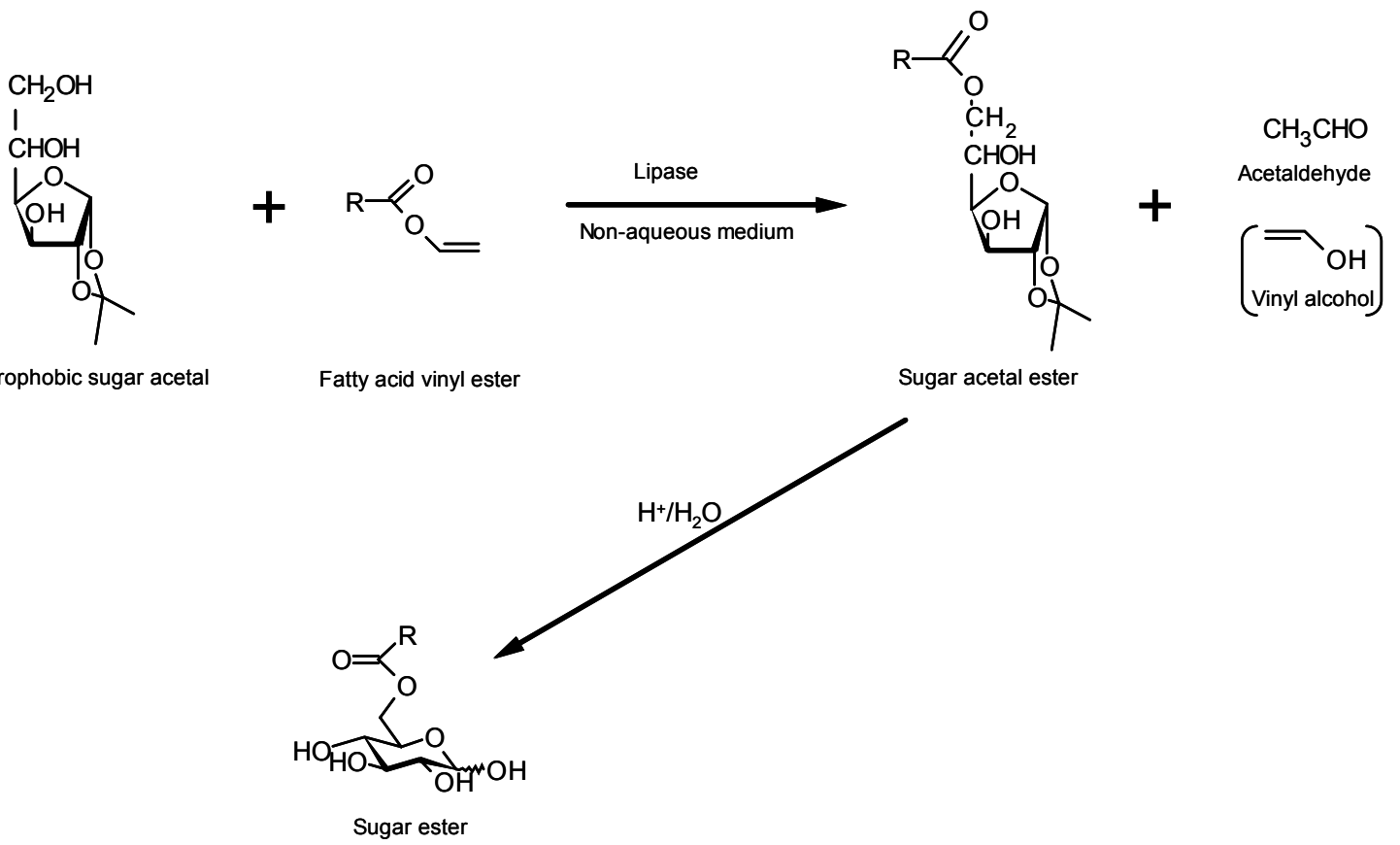

Scheme 2 Synthesis of sugar ester using sugar acetal and fatty acid vinyl ester 
properties of, i.e., the type of organic solvents (Castillo et al. 2003; Kobayashi et al. 2003b; Watanabe et al. 2001). An equilibrium yield is high in hydrocarbons such as hexane, but becomes lower in nitriles, ketones, and tertiary alcohols in this order. The equilibrium yield in TBA+DMSO tends to be much lower. These tendencies are quantitatively related to the difference in the polarity of the solvents in the pure or mixed form (Castillo et al. 2003; Kobayashi et al. 2003b). These facts mean that a change in the type and mixing ratio of the solvents enables us to freely control the equilibrium yield, which Castillo et al. (2003) called 'solvent engineering approach'.

\section{Improvement of reaction rate}

Although dehydrative condensation has the merit that the by-product is water, its reaction rate is not always fast. Therefore, to increase the reaction rate, transesterification is instead often adopted. However, depending on the molecular structure of the substrate, the reaction rate may be sometimes very low. If a carboxylic acid has a carboxyl group with a conjugated double bond (e.g., acrylic acid), its reactivity is much lower than that without a conjugated double bond (Kobayashi et al. 2003a). A similar phenomenon was observed when methacrylic, benzoic, or cinnamic acid was used as the substrate. Therefore, the synthesis of the sugar esters of these carboxylic acids may usually produce a very low yield within a practical reaction period by conventional techniques because of the low solubility of the sugar and the low reactivity of the carboxylic acid.

There are several techniques, such as using an ionic liquid or adding an adjuvant to overcome these drawbacks by improving the solubility of the sugar. Now, the other method is introduced that uses the sugar derivatives as sugar substrates. The solubility of a sugar in an organic solvent can be raised using a hydrophobic sugar derivative instead of an unmodified sugar. There are several hydrophobic derivatives of the sugars: i) phenylboronic acid esters, ii) sugar acetals, and iii) $n$-alkyl glycosides. Phenylboronic acid esters and sugar acetals are usually used for the protection of the hydroxyl groups in sugars. In addition, these protecting groups are also effective to improve the solubility in an organic solvent. Many reports have dealt with the synthesis of sugar esters using hydrophobic sugar derivatives (Table 1, Scheme 2), and some of them succeeded in the production with a high reaction rate and high concentration.

Meanwhile, there are some reports using a polyphenolic glycoside, such as arbutin, rutin, or naringin, which itself has some bioactivities and is a relatively less polar glycoside (Table 1). To further increase the lipophilicity of these compounds, a medium or long chain fatty acid was incorporated into the glycoside 
(Lue et al. 2010; Stevenson et al. 2006; Yang et al. 2010). In addition, the creation of a new bioactivity may be expected when a functional carboxylic acid, such as cinnamic acid, is used as an acyl substrate for esterification of the glycosides (Nakajima et al. 1999; Stevenson et al. 2006).

\section{Conclusion}

The synthesis of a sugar ester using a lipase has been tried for a quarter century, and various kinds of synthetic processes have been suggested. The most important and difficult problem has been how to couple a hydrophobic fatty acid with a hydrophilic sugar at a practical level. To overcome this, improvement in the productivity has been performed by optimizing the types of lipase and the reaction medium based on the solvent engineering, and using hydrophobic sugar derivatives. As a result, it becomes relatively easily to synthesize the target sugar ester on a laboratory scale. The industrialization and further creation of functional sugar esters will be expected by the lipase-catalyzed reaction.

\section{References}

Ardhaoui M, Falcimaigne A, Ognier S, Engasser JM, Moussou P, Pauly G, Ghoul M (2004) Effect of acyl donor chain length and substitutions pattern on the enzymatic acylation of flavonoids. J Biotechnol $110: 265-271$

Castillo E, Pezzotti F, Navarro A, López-Munguía A (2003) Lipase-catalyzed synthesis of xylitol monoesters: solvent engineering approach. J Biotechnol 1024:251-259

Cauglia F, Canepa P (2008) The enzymatic synthesis of glucosylmyristate as a reaction model for general considerations on 'sugar esters' production. Biores Technol 99:4065-4072

Chen J, Kimura Y, Adachi S (2005) Continuous synthesis of 6-O-linoleoyl hexose using a packed-bed reactor system with immobilized lipase. Biochem Eng J 22:145-149

Chen J, Kimura Y, Adachi S (2007) Surface activities of monoacyl trehaloses in aqueous solution. LWT $40: 412-417$

Chopineau J, McCafferty FD, Therisod M, Klibanov AM (1988) Production of biosurfactants from sugar alcohols and vegetable oils catalyzed by lipases in a nonaqueous medium. Biotechnol Bioeng $31: 208-214$

Coulon D, Ismail A, Girardin M, Ghoul M (1998) Enzymatic synthesis of alkylglycoside fatty acid esters catalyzed by an immobilized lipase. J Mol Catal B Enzym 5:45-48 
Cramer JF, Dueholm MS, Nielsen SB, Pedersen DS, Wimmer R, Pedersen LH (2007) Controlling the degree of esterification in lipase catalysed synthesis of xylitol fatty acid esters. Enzym Microb Technol 41:346-352

Diego TD, Lozano P, Gmouh S, Vaultier M, Iborra JL (2005) Understanding structure-stability relationships of Candida antartica lipase B in ionic liquids. Biomacromol 6:1457-1464

Ferrer M, Cruces MA, Bernabé M, Ballesteros A, Plou FJ (1999) Lipase-catalyzed regioselective acylation of sucrose in two-solvent mixtures. Biotechnol Bioeng 65:10-16

Ferrer M, Cruces MA, Plou FJ, Bernabé M, Ballesteros A (2000) A simple procedure for the regioselective synthesis of fatty acid esters of maltose, leucrose, maltotriose and $n$-dodecyl maltosides. Tetrahedron $56: 4053-4061$

Ferrer M, Soliveri J, Plou FJ, López-Cortés N, Reyes-Duarte D, Christensen M, Copa-Patiño JL, Ballesteros A (2005) Synthesis of sugar esters in solvent mixtures by lipases from Thermomyces lanuginosus and Candida antarctica B, and their antimicrobial properties. Enzym Microb Technol $36: 391-398$

Fregapane G, Sarney DB, Vulfson EN (1991) Enzymic solvent-free synthesis of sugar acetal fatty acid esters. Enzym Microb Technol 13:796-800

Gao C, Whitcombe MJ, Vulfson EN (1999) Enzymatic synthesis of dimeric and trimeric sugar-fatty acid esters. Enzym Microb Technol 25:264-270

Ikeda I, Klibanov AM (1993) Lipase-catalyzed acylation of sugars solubilized in hydrophobic solvents by complexation. Biotechnol Bioeng 42:788-791

Kaar JL, Jesionowski AM, Berberich JA, Moulton R, Russell AJ (2003) Impact of ionic liquid physical properties on lipase activity and stability. J Am Chem Soc 125:4125-4131

Katsoura MH, Polydera AC, Katapodis P, Kolisis FN, Stamatis H (2007) Effect of different reaction parameters on the lipase-catalyzed selective acylation of polyhydroxylated natural compounds in ionic liquids. Proc Biochem 42:1326-1334

Khaled N, Montet D, Pina M, Graille J (1991) Fructose oleate synthesis in a fixed catalyst bed reactor. Biotechnol Lett 13:167-172

Kim MJ, Choi MY, Lee JK, Ahn Y (2003) Enzymatic selective acylation of glycosides in ionic liquids: significantly enhanced reactivity and regioselectivity. J Mol Catal B Enzym 26:115-118

Klibanov AM (1986) Enzymes that work in organic solvents. Chemtech 16:354-359 
Klibanov AM (1989) Enzymatic catalysis in anhydrous organic solvents. TIBS 14:141-144

Klyosov AA, van Viet N, Berezin IV (1975) The reactions of $\alpha$-chymotrypsin and related proteins with ester substrates in non-aqueous solvents. Eur J Biochem 59:3-7

Kobayashi T, Adachi S, Matsuno R (2003a) Lipase-catalyzed condensation of $p$-methoxyphenethyl alcohol and carboxylic acids with different steric and electrical properties in acetonitrile. Biotechnol Lett $25: 3-7$

Kobayashi T, Ehara T, Mizuoka T, Adachi S (2010) Efficient synthesis of 6-O-palmitoyl-1,2-O-isopropylidenea-D-glucofuranose in an organic solvent system by lipase-catalyzed esterification. Biotechnol Lett 32:1679-1684

Kobayashi T, Furutani W, Adachi S, Matsuno R (2003b) Equilibrium constant for the lipase-catalyzed synthesis of fatty acid butyl ester in various organic solvents. J Mol Catal B Enzym 24:61-66

Krishna SH, Divakar S, Prapulla SG, Karanth NG (2001) Enzymatic synthesis of isoamyl acetate using immobilized lipase from Rhizomucor miehei. J Biotechnol 87:193-201

Lee SH, Ha SH, Hiep NM, Chang W-J, Koo YM (2008) Lipase-catalyzed synthesis of glucose fatty acid ester using ionic liquids mixtures. J Biotechnol 133:486-489

Lozano P, Diego T, Gmouh S, Vaultier M, Iborra JL (2004) Criteria to design green enzymatic processes in ionic liquid/supercritical carbon dioxide systems. Biotechnol Progr 20:661-669

Lue BM, Guo Z, Glasius M, Xu X (2010) Scalable preparation of high purity rutin fatty acid esters. J Am Oil Chem Soc 87:55-61

Matsuo T, Kobayashi T, Kimura Y, Hosoda A, Taniguchi H, Adachi S (2008) Continuous synthesis of glyceryl ferulate using immobilized Candida antarctica lipase, J Oleo Sci 57:375-380

Moreau B, Lognay GC, Blecker C, Brohée1 JC, Chéry F, Rollin P, Paquot M, Marlier M (2004) Synthesis of novel D-glucuronic acid fatty esters using Candida antarctica lipase in tert-butanol. Biotechnol Lett 26:419-424

Nakajima N, Ishihara K, Itoh T, Furuya T, Hamada H (1999) Lipase-catalyzed direct and regioselective acylation of flavonoid glucoside for mechanistic investigation of stable plant pigments. J Biosci Bioeng 87:105-107

Otto RT, Bornscheuer UT, Syldatk C, Schmid RD (1998) Synthesis of aromatic $n$-alkyl-glucoside esters in a coupled $\beta$-glucosidase and lipase reaction. Biotechnol Lett 20:437-440

Pinsirodom P, Watanabe Y, Nagao T, Sugihara A, Kobayashi T, Shimada Y (2004) Critical temperature for 
production of MAG by esterification of different FA with glycerol using Penicillium camembertii lipase. J Am Oil Chem Soc 81:543-547

Plou FJ, Cruces MA, Ferrer M, Fuentes G, Pastor E, Bernabé M, Christensen M, Comelles F, Parra JL, Ballesteros A (2002) Enzymatic acylation of di- and trisaccharides with fatty acids: choosing the appropriate enzyme, support and solvent. J Biotechnol 96:55-66

Sarney DB, Kapeller H, Fregapane G, Vulfson EN (1994) Chemo-enzymatic synthesis of disaccharide fatty acid esters. J Am Oil Chem Soc 71:711-714

Sarney DB, Barnard MJ, MacManus DA, Vulfson EN (1996) Application of lipases to the regiosolective synthesis of sucrose fatty acid monoesters. J Am Oil Chem Soc 73:1481-1487

Somashekar BR, Divakar S (2007) Lipase catalyzed synthesis of L-alanyl esters of carbohydrates. Enzym Microb Technol 40:299-309

Stamatis H, Sereti V, Kolisis FN (2001) Enzymatic synthesis of hydrophilic and hydrophobic derivatives of natural phenolic acids in organic media. J Mol Catal B Enzym 11:323-328

Stevenson DE, Wibisono R, Jensen DJ, Stanley RA, Cooney JM (2006) Direct acylation of flavonoid glycosides with phenolic acids catalysed by Candida antarctica lipase B (Novozym $435^{\circledR}$ ). Enzym Microb Technol 39:1236-1241

Therisod M, Klibanov AM (1986) Facile enzymatic preparation of monoacylated sugars in pyridine. J Am Chem Soc 108:5638-5640

Vijayakumar GR, Lohith K, Somashekar BR, Divakar S (2004) Lipase catalyzed synthesis of L-alanyl, L-leucyl and L-phenylalanyl esters of D-glucose using unprotected amino acids. Biotechnol Lett $26: 1323-1328$

Watanabe Y, Miyawaki Y, Adachi S, Nakanishi K, Matsuno R (2000) Synthesis of lauroyl saccharides through lipase-catalyzed condensation in microaqueous water-miscible solvents. J Mol Catal B Enzym 10:241-247

Watanabe Y, Miyawaki Y, Adachi S, Nakanishi K, Matsuno R (2001) Equilibrium constant for lipase-catalyzed condensation of mannose and lauric acid in water-miscible organic solvents. Enzym Microb Technol 29:494-498

Watanabe Y, Shimada Y, Yamauchi-Sato Y, Kasai M, Yamamoto T, Tsutsumi K, Tominaga Y, Sugihara A (2002) Synthesis of MAG of CLA with Penicillium camembertii lipase. J Am Oil Chem Soc 79:891-896 
Watanabe Y, Yamauchi-Sato Y, Nagao T, Negishi S, Terai T, Kobayashi T, Shimada Y (2005) Production of MAG of CLA by esterification with dehydration at ordinary temperature using Penicillium camembertii lipase. J Am Oil Chem Soc 82:619-623

Yamauchi-Sato Y, Watanabe Y, Nagao T, Negishi S, Kobayashi T, Shimada Y (2005) Production of diglycerol conjugated linoleic acid monoester by esterification with Penicillium camembertii lipase. J Oleo Sci 9:481-486

Yang RL, Li N, Li RF, Smith TJ, Zong MH (2010) A highly regioselective route to arbutin esters by immobilized lipase from Penicillium expansum. Biores Technol 101:1-5

Yu HL, Xu JH, Su JH, Lu WY, Lin GQ (2008) Synthesis of novel salidroside esters by lipase-mediated acylation with various functional acyl groups. J Biosci Bioeng 106:65-68

Zhao H, Baker GA, Song Z, Olubajo O, Crittlea T, Peters D (2008) Designing enzyme-compatible ionic liquids that can dissolve carbohydrates. Green Chem 10:696-705 